\title{
Expression of Stathmin, a Developmentally Controlled Cytoskeleton-Regulating Molecule, in Demyelinating Disorders
}

\author{
Aixiao Liu, ${ }^{1}$ Christine Stadelmann, ${ }^{2}$ Mario Moscarello, ${ }^{3}$ Wolfgang Bruck, ${ }^{2,4}$ Andre' Sobel, ${ }^{5}$ Fabrizio G. Mastronardi, ${ }^{3}$ \\ and Patrizia Casaccia-Bonnefil ${ }^{1}$ \\ ${ }^{1}$ Department of Neuroscience, R. Wood Johnson Medical School, Piscataway, New Jersey 08854, ${ }^{2}$ Department of Neuropathology, University of Goettingen, \\ 13353 Goettingen, Germany, ${ }^{3}$ Department of Biochemistry, Hospital for Sick Children, Toronto, Ontario, M5G 1X8 Canada, ${ }^{4}$ Hertie Institute of Multiple \\ Sclerosis Research, 13353 Goettingen, Germany, and 5Unité 440 Institut National de la Santé et de la Recherche Médical, Institut du Fer a’ Moulin Paris, \\ 75005 Paris, France
}

Understanding the biological relevance of reexpression of developmental molecules in pathological conditions is crucial for the development of new therapies. In this study, we report the increased expression of stathmin, a developmentally regulated tubulin-binding protein, in the brains of patients with multiple sclerosis (MS). In physiological conditions, stathmin immunoreactivity was observed in polysialic acid-neural cell adhesion molecule-positive migratory progenitors in the subventricular zone, and its expression progressively decreased as the cells matured into oligodendrocytes (OLs). In MS patients, however, stathmin levels were elevated in $2^{\prime}, 3^{\prime}$-cyclic nucleotide $3^{\prime}$-phosphodiesterase-positive OLs, in 10 of 10 bioptic samples analyzed. Increased levels of stathmin were confirmed by Western blot analysis of normal-appearing white matter samples from MS brains. In addition, using mass spectrometry, stathmin was identified as the main component of a specific myelin protein fraction consistently increased in MS preparations compared with controls.

To test the biological relevance of increased stathmin levels, primary OL progenitors were transfected using a myc-tagged stathmin cDNA and were allowed to differentiate. Consistent with a distinct role played by this molecule in cells of the OL lineage at different developmental stages, transient transfection in progenitors favored the bipolar migratory phenotype but did not affect survival. However, sustained stathmin levels in differentiating OLs, because of overexpression, resulted in enhanced apoptotic susceptibility.

We conclude that stathmin expression in demyelinating disorders could have a dual role. On one hand, by favoring the migratory phenotype of progenitors, it may promote myelin repair. On the other hand, stathmin in mature OLs may indicate cell stress and possibly affect survival.

Key words: multiple sclerosis; myelin; oligodendrocyte; microtubule; repair; demyelination

\section{Introduction}

The reexpression of developmental molecules has been documented in several pathological states, including liver and lung cancer (Hafner et al., 2004), kidney fibrosis (Sequeira Lopez and Gomez, 2004), Alzheimer's disease (Riedel et al., 2003), and multiple sclerosis (MS) (John et al., 2002), but the biological significance of this phenomenon remains only partially defined.

Here, we describe high levels of the tubulin sequestering and

Received July 9, 2004; revised Nov. 24, 2004; accepted Nov. 29, 2004.

This work was supported by National Institutes of Health-National Institute of Neurological Disorders and Stroke Grant R01-NS42925 (P.C.-B.), National Multiple Sclerosis Society Grant RG3421-A-4 (P.C.-B.), funds from the Association Recherche Sclerose En Plaque (A.S.), grants from the Multiple Sclerosis Society of Canada (F.G.M., M.M.), and funds from the Gemeinnutzige Hertie-Stiftung and the University of Goettingen (C.S.). We acknowledge Ralph Rosa and the Multiple Sclerosis Research Foundation for generous support and constant encouragement; Tereska Miani, Mei Jiang, and Jiadong Li for technical support; Noriko Goldsmith for confocal assistance; Dr. Y. M. She for mass spectrometry; and Dr. David Crockett for the use of the sterotactic apparatus. We are very grateful to Dr. Sergio Baranzini for sharing information, to Dr. Wallace Tourtellotte and James Rehl (UCLA Brain Tissue Bank, Los Angeles, (A), and to the Canadian Brain Tissue Bank (Toronto, Ontario, Canada) for providing the human samples.

Correspondence should be addressed to Dr. Patrizia Casaccia-Bonnefil, Department of Neuroscience, R-304, R. Wood Johnson Medical School, 675 Hoes Lane, Piscataway, NJ 08854. E-mail: casaccpa@umdnj.edu.

DOI:10.1523/JNEUROSCI.4174-04.2005

Copyright $\odot 2005$ Society for Neuroscience $\quad$ 0270-6474/05/250737-11\$15.00/0 cytoskeleton interfering protein stathmin in demyelinating disorders and ask the biological relevance of this finding. Stathmin is a highly conserved protein among vertebrates (Koppel et al., 1990) that is highly expressed during embryogenesis and progressively declines during the development of the brain and spinal cord (Amat et al., 1991; Pellier-Monnin et al., 2001). Stathmin is part of a larger protein family (Schubart et al., 1989; Okazaki et al., 1993; Ozon et al., 1997) including the neural proteins SCG10 (Anderson and Axel, 1985), SCLIP (Ozon et al., 1998), RB3, and the spliced isoforms RB3' and RB3" (Ozon et al., 1997, 1998). It was originally identified as a cytosolic phosphoprotein in neuroendocrine cells (Sobel and Tashjian, 1983; Schubart, 1988), also called Op18 (Hailat et al., 1990) and p19 (Pasmantier et al., 1986), and then identified in high abundance in the developing brain (Schubart et al., 1989; Koppel et al., 1990; Amat et al., 1991). In the adult brain, stathmin has been detected in germinal areas with neurogenic and gliogenic potential (Amat et al., 1991) and in specific subpopulations of neurons (Peschanski et al., 1993; Camoletto et al., 1997; Ozon et al., 1999), although its expression in neurons is much lower than SCG10 (Himi et al., 1994). 
Stathmin has been shown to increase the rate of microtubule catastrophe by direct interaction with tubulin dimers and inhibition of tubulin polymerization (Belmont and Mitchison, 1996; Curmi et al., 1997; Charbaut et al., 2001). We have previously identified stathmin as one of the genes encoding for cytoskeletal elements that were epigenetically downregulated during oligodendrocyte progenitor differentiation in vitro (A. Liu et al., 2003). Because of the importance of the microtubule network as structural support for the myelin membrane and transport system of myelin components (Wilson and Brophy, 1989; Ainger et al., 1993; Benjamins and Nedelkoska, 1994; Carson et al., 1998; Song et al., 2001), we now asked whether stathmin was expressed in pathological conditions associated with myelin dysfunction.

\section{Materials and Methods}

Primary cultures of oligodendrocyte progenitors from the neonatal rat brain. Oligodendrocyte progenitors were isolated from the cortex of postnatal day 1 rats and cultured according to a modified McCarthy and de Vellis procedure (1980), as described by A. Liu et al. (2003).

Immunocytochemistry on primary cultures. Cells were grown on Permanox chambers for all immunocytochemistry. For oligodendrocyte lineage staining, cells were rinsed gently with PBS, incubated with O4 hybridoma supernatant (1:10; a gift from Dr. R. Bansal, University of Connecticut Health Center, Farmington, CT) for $30 \mathrm{~min}$ at $37^{\circ} \mathrm{C}$, and then fixed with $4 \%$ paraformaldehyde (PFA). For immunofluorescence, cells were incubated with antibodies against stathmin (1:1000; Calbiochem, San Diego, CA), Myc-Tag (1:500; Upstate Biotechnology, Lake Placid, NY), and green fluorescent protein (GFP) (1:8000; Chemicon, Temecula, CA) for $1 \mathrm{~h}$, followed by incubation with the appropriate secondary antibodies conjugated with fluorophores. Immunoreactive cells were analyzed using a fluorescence microscope (Leica DM-RA; Leica, Nussloch, Germany), and the images were captured using a Hamamatsu (Hamamatsu City, Japan) CCD camera interfaced with a G4 computer.

Ethidium bromide injection. Eight-week-old C57BL/6 mice (10 mice) were anesthetized using a mixture of Nembutal $(6 \mathrm{mg} / \mathrm{ml})$ and xylazine $(0.58 \mathrm{mg} / \mathrm{ml})$ at a dose of $7.5 \mu \mathrm{l}$ per gram of body weight. A small incision was made on the scalp to expose the skull and drill a small hole. A micropipette attached to a Hamilton syringe was used for the delivery of $1 \mu \mathrm{l}$ of a $0.1 \%$ ethidium bromide, using the following stereotactic coordinates: right, $1.2 \mu \mathrm{m}$; anterior to bregma, $0.5 \mu \mathrm{m}$; depth, $1.2 \mu \mathrm{m}$; according to the atlas of Franklin and Paxinos (1997). The hole was closed using gelfoam, and the skin was sutured. The animals were allowed to recover on a heated pad and were kept for two survival points: $4 \mathrm{~d}$ after injection $(n=5)$ and 2 weeks after injection $(n=5)$.

Immunohistochemistry of brain sections from adult mice. Mice were perfused with $4 \%$ PFA, and the brains were removed. After postfixation in $4 \%$ PFA, the brains of the mice used for the developmental studies and those of the mice used for ethidium bromide injection were kept in 30\% sucrose and then cryopreserved.

Cryosections of $20 \mu \mathrm{m}$ thickness were permeabilized by a $10 \mathrm{~min}$ incubation in $-20^{\circ} \mathrm{C}$ methanol, washed, and blocked with $10 \%$ NGS in a phosphate-based buffer containing $0.1 \%$ gelatin, $1 \%$ bovine serum albumin, and $0.5 \%$ Triton X-100 (PGBA). The primary antibody against stathmin was obtained from Calbiochem and consisted of a polyclonal antiserum raised against a C-terminal epitope of stathmin. The primary antibody was used at a dilution of 1:1000 in PGBA and incubated overnight at room temperature. Secondary anti-rabbit antibody conjugated with rhodamine (Jackson ImmunoResearch, West Grove, PA) was used at a dilution of 1:200 for $1 \mathrm{~h}$ at room temperature. Migratory precursors were labeled using anti-polysialic acid-neural cell adhesion molecule (PSA-NCAM) antibodies (1:400; AbCys, Paris, France). Oligodendrocyte progenitors were identified using NG2 antibodies (Chemicon) and Sox10 antibodies (1:1000; a kind gift from Dr. M. Wegner, Institut für Biochemie, Erlangen, Germany). Oligodendrocytes were labeled using the monoclonal antibody against adenomatous polyposis coli (APC; clone CC1) (Oncogene, San Diego, CA) at a dilution of 1:30; astrocytes were detected using anti-GFAP (1:1000; Dako, Carpinteria, CA), and axonal staining was performed using anti-neurofilaments (1:200; Chemicon). Biotinylated secondary antibodies followed by FITCconjugated avidin were used for the detection of the labeled cells. Confocal images were obtained using an LSM510 Meta confocal laserscanning microscope (Zeiss, Oberkochen, Germany). The LSM5 Image Browser software was used for image acquisition.

Immunohistochemistry of human brain sections. Ten biopsies from MS patients, four biopsies from patients with temporal lobe epilepsy, and four autopsy brains of patients with no neurological diseases were examined. Biopsies on MS patients were performed for diagnostic purposes. Tissue was formalin fixed and paraffin embedded. After deparaffinization and rehydration, sections were pretreated with microwaving (except for stathmin) in $10 \mathrm{~mm}$ citrate buffer as described previously (Stadelmann et al., 2002). Primary antibodies [stathmin, 1:500 (Calbiochem); anti-CNPase, 1:200 (Sternberg Monoclonals, Lutherville, MD); myelin basic protein (MBP), 1:500 (Dako)] were incubated overnight at $4^{\circ} \mathrm{C}$. Biotinylated secondary antibodies (Amersham, Piscataway, NJ) were followed by avidin-peroxidase (Sigma, St. Louis, MO), followed by diaminobenzidine as a chromogenic substrate and hematoxylin counterstain. For immunofluorescence stainings, specific immunoreactivity was detected with secondary antibodies coupled with $\mathrm{Cy} 2$ and $\mathrm{Cy} 3$ fluorophores, followed by treatment with $0.5 \%$ Sudan black in $70 \%$ ethanol to suppress autofluorescence and 4',6-diamidino-2-phenylindole (DAPI) as counterstain. Pictures were taken using an Olympus BX51 fluorescence microscope equipped with a CCD camera (Color View II; Soft Imaging System).

Stathmin identification in the C8a fraction isolated from myelin preparation of MS and control brains. Myelin was prepared from white matter samples of normal $(n=3)$ and MS $(n=4)$ human brains, as described previously (Wood and Moscarello, 1989). MBP and its variously charged isomers were separated by CM52 cation exchange chromatography, into several fractions defined $\mathrm{C} 1$ to $\mathrm{C} 8$, as described previously (Cheifetz and Moscarello, 1985). The unbound protein fraction appearing in the void volume was defined as "C8" and further purified by HPLC into two components defined as "C8a" and "C8b," both containing proteins of a molecular weight in the 17-18 kDa range (Boulias et al., 1995). Stathmin was identified as the main component within the C8a fraction by matrixassisted laser desorption/ionization-time of flight (MALDI-TOF) mass spectrometry. Briefly, protein components of the C8a fractions from MS and control white matter samples were separated by $12.5 \%$ SDS-PAGE, the gels were stained with amido black, and the 17-18 kDa bands of interest were excised and trypsinized as described previously (She et al., 2002). Trypsinized fragments were analyzed using an Applied Biosystems/MDS Sciex (Concord, Ontario, Canada) Qstar x 2 MALDI Q2 TOF mass spectrometer at the Advanced Protein Center in The Hospital for Sick Children in Toronto. The matrix used was 2,5-dihydroxybenzoic acid in acetonitrile/water $(1: 1 \mathrm{v} / \mathrm{v})$. The peptide fragment with 1388.761 amu of the $18 \mathrm{kDa}$ band in the C8a sample was sequenced by tandem mass spectrometry, then submitted to the MASCOT search engine (www. matrixscience.com/) at the National Center for Biotechnology Information database.

Western blots and slot blot quantitation. Whole-cell lysates were prepared from cultured progenitors or differentiated oligodendrocyte as described previously (A. Liu et al., 2003). Normal-appearing white matter samples from MS patients $(n=6)$ and control brains $(n=4)$ were obtained from the UCLA Brain Tissue Bank (to P.C.-B.) and from the Canadian Brain Tissue Bank (to M.M.). Whole protein lysates were obtained from these samples, by incubation in $50 \mathrm{~mm}$ Tris buffer, $\mathrm{pH} 7.5$, containing 1\% SDS, 1 mм DTT, 1 mм EDTA, 1 mм PMSF, 1 mm aprotinin, and $1 \mathrm{~mm}$ leupeptin for $15 \mathrm{~min}$ on ice. For the Western blot analysis of the C8 fractions, samples were prepared from MS patients $(n=3)$ and control brains $(n=4)$ as described above. Western blot analysis was performed by incubating nitrocellulose membrane with a monoclonal antibody recognizing MBP (MAb26) and with the rabbit polyclonal stathmin antibody (Calbiochem), raised against the last C-terminal aa 134-149 of the molecule (Koppel et al., 1990). The detection of the phosphorylated forms of stathmin was obtained by Western blot analysis using specific antibodies [generated by A.S. and characterized in the 
study by Gavet et al. (2002)] against phosphoserine S16, S25, or S38, used at a dilution of 1:20,000. Immunoreactive bands were identified with horseradish peroxidase-conjugated secondary antibodies, followed by chemiluminescence (Amersham). For slot blot analysis and quantification, the protein samples were diluted with $3 \mathrm{M}$ urea in PBS, pH 7.4 to 100 $\mu \mathrm{g} / \mathrm{ml}$ protein. The amounts of stathmin and phosphostathmin (S16P, $\mathrm{S} 25 \mathrm{P}, \mathrm{S} 38 \mathrm{P}$ ) were determined by placing $5 \mu \mathrm{g}$ of protein in $50 \mu \mathrm{l} / \mathrm{slot}$ onto wetted nitrocellulose membrane in a Biodot (SF) ultrafiltration unit (Bio-Rad, Hercules, CA) under vacuum. The amount of stathmin in the C8a fraction from MS patients was expressed as the ratio over the levels in the C8a fraction from normal brain. The relative amounts were then corrected for the yield of $\mathrm{C} 8 \mathrm{a}$ isolated for each individual preparation. This correction factor accounts for the total amount of stathmin in the C8a fractions. Each experiment was performed in triplicate.

Transfection of myc-tagged stathmin in cultured oligodendrocyte progenitors. A2B5 immunoselected oligodendrocyte progenitors were transfected using the Rat Oligodendrocyte Nucleofector kit (Amaxa, Gaithersburg, MD) according to the manufacturer's instructions. Briefly, $1 \mu \mathrm{g}$ of pcDNA carrying myc-tagged human stathmin (Lawler et al., 1998) or enhanced GFP (EGFP) was electroporated into $5 \times 10^{6}$ cells. After a 15 min incubation with DMEM plus $10 \%$ FBS, $2 \times 10^{4}$ cells/well were plated in Permanox slide chambers coated with either poly-lysine $(0.1$ $\mathrm{mg} / \mathrm{ml}$ in $\mathrm{H}_{2} \mathrm{O}$; Sigma) or laminin ( $20 \mu \mathrm{g} / \mathrm{ml}$ in PBS buffer; Sigma) for $18 \mathrm{~h}$ and then replaced with chemically defined oligodendrocyte differentiation medium. For the analysis of morphological differentiation, cells were classified as described by A. Liu et al. (2003).

Effect of increased levels of stathmin on cell death induced by glucose deprivation. For the susceptibility to apoptosis, progenitors were transfected with mammalian expression vectors containing myc-stathmin. Cells transfected with EGFP or empty vector (pcDNA) were used as controls. Progenitors were induced to differentiate by mitogen deprivation in the presence or in the absence of limiting amounts of glucose in the medium. After 24 and $72 \mathrm{~h}$ in these culture conditions, cultures were washed twice with PBS, to remove all the loosely attached cells, then stained live with the anti-O 4 antibody and fixed by incubation in $4 \%$ PFA for $20 \mathrm{~min}$ at room temperature. After processing the samples for immunohistochemistry, the number of surviving cells was evaluated in the control and in the myc-stathmin-transfected cultures. The number of surviving cells was then counted in the myc-stathmin- and EGFPtransfected cultures. The total number of surviving cells in the EGFPtransfected culture was arbitrarily set as $100 \%$, and the number of cells in the stathmin-transfected culture was referred to this arbitrary value. To further demonstrate that the decreased number of cells in the stathmin overexpressors was attributable to decreased survival, we performed terminal deoxynucleotidyl transferase-mediated biotinylated UTP nick end labeling (TUNEL). Briefly, myc-tagged stathmin-transfected cells and pcDNA controls were labeled using DAPI, to identify all of the cell nuclei, and the ApopTag plus kit (Chemicon), to identify apoptotic cells. DAPI+ nuclei and apoptotic green nuclei were counted in both culture conditions, and the values were presented as the percentage of apoptotic cells relative to the total number of DAPI+ cells.

\section{Results}

Stathmin expression is high in primary cultures of oligodendrocyte progenitors and decreases during oligodendrocyte differentiation in vitro

We have previously reported that process outgrowth during oligodendrocyte differentiation correlates with downregulation of genes encoding for cytoskeletal depolymerizing proteins, including stathmin (A. Liu et al., 2003). We now asked whether stathmin protein was expressed in primary cultures of rat cortical immunoselected oligodendrocyte progenitors and whether its levels were downregulated by differentiative stimuli. High levels of stathmin were detected in the soma and cytoplasmic processes of bipolar progenitors, cultured in the presence of PDGF and basic FGF (bFGF), and identified by A2B5 immunoreactivity (Fig. 1a,b). Differentiation induced by mitogen withdrawal resulted in the redistribution of stathmin to a perisomatic location
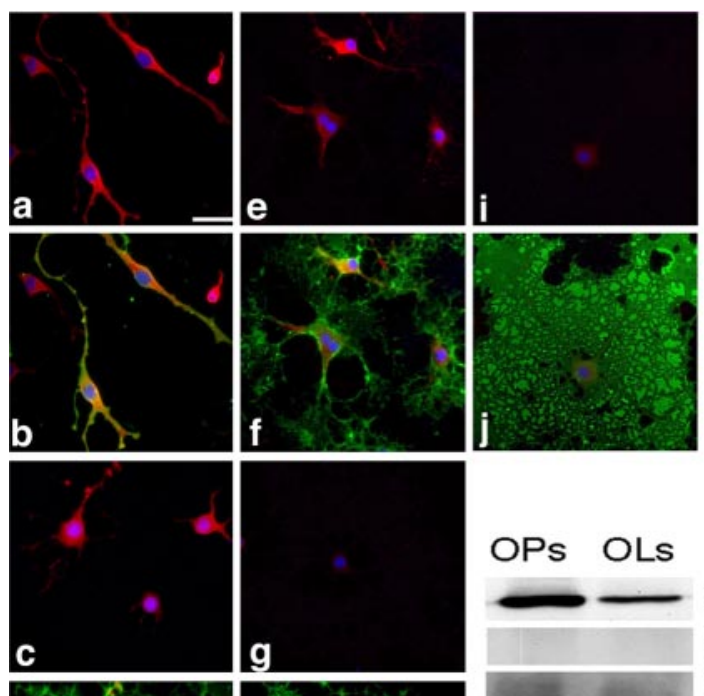

stathmin
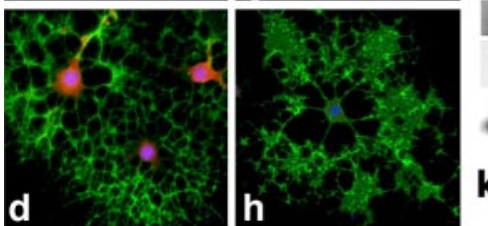

S16

S25 S38

Figure 1. Progressive decrease of stathmin levels during oligodendrocyte morphological differentiation in vitro. Immunofluorescent staining of stathmin (red) in neonatal primary rat cortical progenitors cultured on poly-lysine-coated slides $(a-f)$ and maintained undifferentiated in medium containing PDGF plus bFGF $(a, b)$ or differentiated by mitogen withdrawal $(c, d)$ or by PDGF plus $\mathrm{T} 3$ treatment $(e, f)$ for $3 \mathrm{~d}$ are shown. Morphological differentiation and myelin membrane formation was also assessed by culturing cells on laminin-coated slides $(g-j)$ in the presence of PDGF plus T3 $(g, h)$ or in the absence of mitogens $(i, j)$. Undifferentiated bipolar progenitors were identified by positive immunoreactivity for the early oligodendrocyte progenitor marker A2B5 (green; $b$ ), whereas branched developing oligodendrocytes were identified by 04 immunoreactivity (green; $d, f, h, j$ ). Note that stathmin immunoreactivity (red; $a-j$ ) was reduced during differentiation in vitro and that growth on laminin further decreased its levels and confined its localization to the soma of the differentiated cells $(g, i)$ with complete exclusion from the cytoplasmic processes and the myelin membrane (j). Scale bar, $40 \mu \mathrm{m}$. Phosphorylated stathmin was detected by Western blot analysis ( $k$ ) using antibodies generated against specific phosphorylated serine residues, such as serine 16 (S16), serine 25 (S25), and serine 38 (S38). Note that stathmin was weakly phosphorylated on residues 25 and 38 . Actin was used as a loading control.

within $24 \mathrm{~h}$ (Fig. 1c,d). Similar results were observed after $3 \mathrm{~d}$ of differentiation in the presence of PDGF and thyroid hormone (Fig. 1e,f). It is well established that culturing progenitors on laminin substrate results in the elaboration of large myelin membranes (Fig. 1j). Given the importance of microtubule stability for myelin membrane formation and function, we also tested the effect of laminin on stathmin levels. In agreement with the necessity of a stable microtubule network for myelin maintenance, growth on laminin dramatically reduced stathmin levels in the mature myelin-forming cells (Fig. $1 g-j$ ). These results support the downregulation of stathmin levels and its subcellular redistribution during the differentiation of progenitors into myelinforming oligodendrocyte in vitro.

An additional level of regulation of stathmin function is the phosphorylation of specific serine residues at positions 16 (S16), 25 (S25), and 38 (S38) of the molecule. To address the role of stathmin phosphorylation in developing oligodendrocytes in vitro, we used phosphorylation-specific antibodies in immunocytochemistry (data not shown) and Western blot analysis (Fig. $1 k$ ). Progenitors or differentiated oligodendrocytes did not show any immunoreactivity with antibodies against S16 phosphostathmin. A weak immunoreactivity could be detected in progen- 
itors and in mature oligodendrocytes stained with antibodies against S25 and S38 phospho-stathmin (Fig. $1 k$ ). We conclude that stathmin function during oligodendrocyte differentiation is prevalently regulated by controlling the protein levels.

Stathmin immunoreactivity is observed in progenitors residing in the adult subventricular zone in physiological conditions and is increased in demyelinating conditions induced by ethidium bromide injection

Previous studies have reported high stathmin expression levels in neural and glial progenitors during development, followed by a progressive decrease in its levels (Schubart et al., 1989; Amat et al., 1991). Using immunohistochemistry on frozen brain sections, we were able to detect strong stathmin immunoreactivity in areas containing adult multipotent progenitor cells, such as the subventricular zone (SVZ) (Fig. 2a). These cells have been previously characterized to also express the A2B5 antigen (Decker et al., 2000), the polysialated form of the cell adhesion molecule NCAM (PSA-NCAM), and to be highly migratory (Ben-Hur et al., 1998). These SVZ precursors tend to primarily form neuroblasts in physiological conditions (Doetsch et al., 1997) and oligodendrocytes in pathological conditions (NaitOumesmar et al., 1999; Decker et al., 2002; Picard-Riera et al., 2002). Consistent with a role of stathmin in microtubule depolymerization and possibly migration, the stathmin + cells were also PSA-NCAM+

(Fig. $2 a-c$ ). The levels of stathmin were dramatically reduced as cells differentiated toward the oligodendrocyte lineage. Stathmin levels were decreased as the cells acquired a stellate morphology characteristic of the NG2 + stage (data not shown), although very few NG2+/stathmin + cells could be detected in the proximity of the SVZ. As progenitors matured into $\mathrm{CC} 1+$ oligodendrocytes, stathmin immunoreactivity decreased further (Fig. $2 d-f$ ). Occasional stathmin-immunoreactive cells were observed in the corpus callosum. These cells were characteristically arranged in linear arrays, parallel to the axons. They did not stain with antibodies against the oligodendrocytic marker CC1 (Fig. $2 d-f$ ) or with antibodies against MBP (data not shown). These cell were also GFAP negative (Fig. $2 g-i$ ) and neurofilament negative (Fig. $2 j-l$ ).

Because adult progenitors in the SVZ have been shown to be mobilized in response to demyelinating conditions in the brain (Nait-Oumesmar et al., 1999; Decker et al., 2002), we asked whether the mobilized cells were also stathmin immunoreactive. A localized lesion was induced in the corpus callosum of 8-weekold mice (Fig. $3 a-c$ ), using the ethidium bromide injection paradigm (Woodruff and Franklin, 1999). The close proximity of the lesion to the SVZ was selected to determine whether stathmin expression would increase during the 3-4 d period after the injection, when oligodendrocyte progenitors begin to repopulate the lesion site (Levine and Reynolds, 1999). Consistent with the
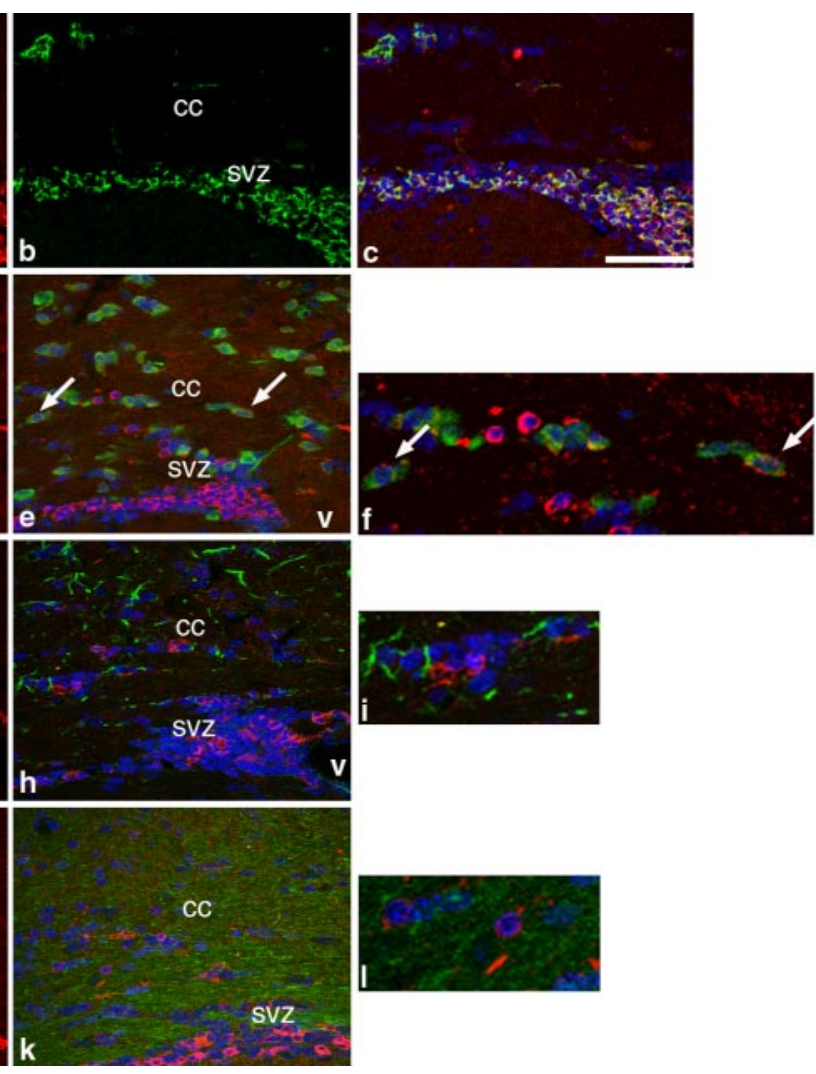

k

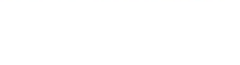

Figure 2. Stathmin is expressed in cells of the SVZ and in the corpus callosum. Confocal images $(a-I)$ of the mouse corpus (CC) and SVZ stained with stathmin (red) and with antibodies specific for the migratory SVZ progenitors PSA-NCAM (green; $b, c)$, the oligodendrocytic marker APC/CC1 (green; $e, f$ ), the astrocytic marker GFAP (green; $h$, $i$ ), and the axonal marker neurofilament NF-M (green; $k, l$ ) are shown. DAPI (blue) was used as a nuclear counterstain. Note that intense stathmin immuhigh-power view of the same field $(f$ ). Note that stathmin immunoreactivity did not colocalize with the astrocytic marker GFAP $(g-i)$ or with the axonal marker neurofilament NF-M $(j-l)$. In contrast, the vast majority of the stathmin-positive cells in the SVZ were PSA-NCAM positive $(a-c)$. Scale bar, $50 \mu \mathrm{m}$.

high levels of stathmin in migratory progenitors, a large increase in the number of immunoreactive cells was detected in the region between the SVZ and the lesion in the injected side (Fig. 3c), whereas only few stathmin + cells were detected in the SVZ of the uninjected side (Fig. $3 b$ ). Several stathmin + cells were colabeled by antibodies specific for the oligodendrocyte progenitor marker Sox 10 (Fig. $4 a-c$ ) or by antibodies recognizing the migratory cell marker PSA-NCAM (Fig. $4 d-f$ ). No CC1+ cells were detected around the lesion site at the $4 \mathrm{~d}$ survival time (data not shown). Two weeks after the injection, however, when the lesion site began to get repopulated by $\mathrm{CC} 1+$ oligodendrocytes, we observed a decrease in the stathmin level, similar to what was described previously, and the $\mathrm{CC} 1+$ cells were consistently stathmin negative (Fig. $4 g-i$ ).

Together, these data indicate that stathmin expression in the SVZ is a physiological response associated with migratory populations of PSA-NCAM+ progenitors.

\section{Stathmin expression is increased in oligodendrocytes in the brain of patients with MS}

The increased expression of stathmin was also observed in oligodendrocytes in the demyelinated human brain. Briefly, paraffinembedded sections were obtained from brain biopsies of $10 \mathrm{MS}$ patients and 8 controls. As shown in Fig. 5, stathminimmunoreactive cells were detected only occasionally in the brain 


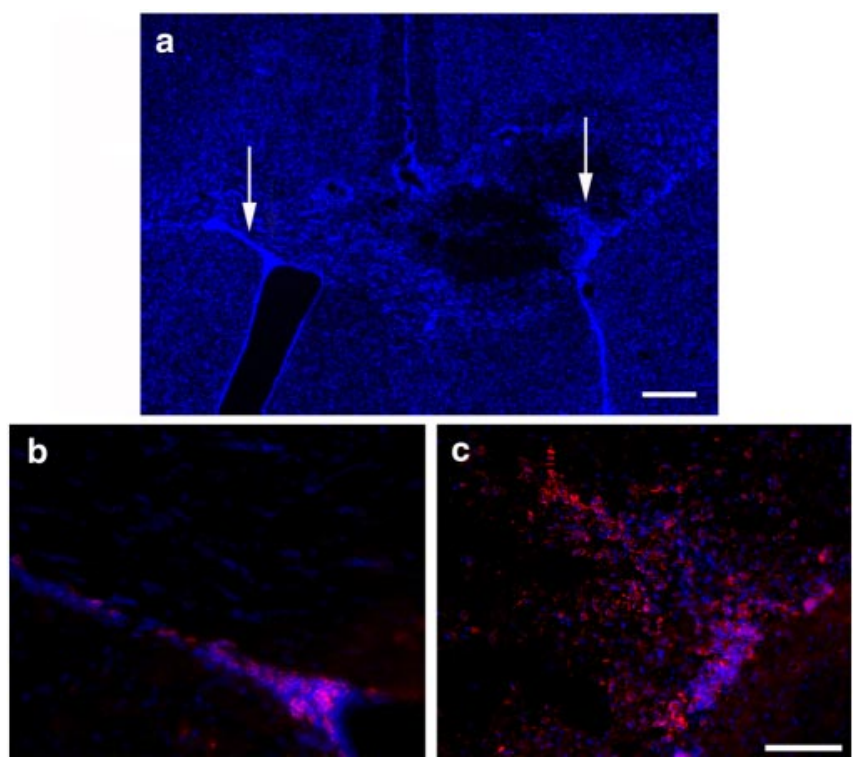

Figure 3. Stathmin expression in SVZ migratory progenitors is increased in response to chemically induced demyelination. Demyelination was induced by ethidium bromide injection in the corpus callosum on the right side. Four days after injection, mice were perfused, and the brains were removed and cryosectioned. DAPI staining (blue) was performed to detect the nuclei of the cells and to reveal cell loss on the injected side ( $a$, right arrow) compared with the noninjected side ( $a$, left arrow). Immunofluorescence staining using antibodies against stathmin (red; $b, c$ ) revealed a larger number of stathmin-positive cells in the SVZ and in the region surrounding the lesion site ( $c$ ) compared with the noninjected side (b). Scale bars: $a, 100 \mu \mathrm{m} ; b, c, 50 \mu \mathrm{m}$.

of control subjects without any neurological disease (Fig. 5a), whereas numerous immunoreactive oligodendrocytes were observed in 10 of $10 \mathrm{MS}$ bioptic samples (Fig. 5b). In our staining conditions, no stathmin-positive axons or axonal spheroids were observed in the lesion (Fig. $5 c$ ) or in the cortex adjacent to the lesion site, although occasional positive astrocytes could be detected in 3 of $10 \mathrm{MS}$ lesions. The intracellular localization of stathmin immunoreactivity was predominant in the soma, although several processes appear to be stained as well (Fig. $5 c$ ). The identification of the stathmin-positive cells as oligodendrocytes was based on size and nuclear morphology and further confirmed by double immunofluorescence with specific markers such as CNPase (Fig. $5 d-f$ ) and CC1 (Fig. $5 g-i$ ). The average number of stathmin-positive CNP+ oligodendrocytes (obtained by counting the number of immunoreactive cells in the $10 \mathrm{MS}$ samples) in the lesion was $77.2 \pm 26$ cells $/ \mathrm{mm}^{2}$ compared with 0 cells $/ \mathrm{mm}^{2}$ in normal tissue biopsies. In the periplaque white matter, the number of cells was much lower than at the lesion site but still higher than in the normal-appearing white matter. To determine a possible association between stathmin immunoreactivity and the pathology of the lesion, we conducted a detailed analysis of the bioptic material. Demyelination and remyelination were defined according to previously described criteria, including proteolipid protein (PLP) in situ hybridization; MBP, MAG, and myelin oligodendrocyte glycoprotein (MOG) immunoreactivity; as well as the appearance and thickness of myelin (Bruck and Stadelmann, 2003). Together, these data revealed the lack of correlation between stathmin immunoreactivity and a specific lesion type, suggesting that this protein is expressed in cells of the oligodendrocyte lineage at different developmental stages.

These morphological data were substantiated by a thorough biochemical analysis of white matter samples from MS patients compared with controls.

To further confirm that stathmin was increased in MS pa- tients, the normal-appearing white matter from MS patients $(n=$ $4)$ and control brains $(n=3)$ was acid extracted and fractionated by cation exchange chromatography on a CM52 column, as described by Wood and Moscarello (1989). The isolated fractions were called $\mathrm{C} 1, \mathrm{C} 2, \mathrm{C} 3$, and $\mathrm{C} 4$. The $\mathrm{C} 8$ component represented the void volume of the CM2 column and was further purified using HPLC into a C8a and C8b fraction (Fig. 6a). Coomassie blue staining of proteins from each fraction, separated by SDS gel electrophoresis, revealed the presence of prominent bands $\sim 17-18 \mathrm{kDa}$ (Fig. $6 b$ ). Although the relative yield of fractions $\mathrm{C} 1$ to $\mathrm{C} 4$ was consistently lower in MS patients, whereas the yield of fractions C8a and C8b was dramatically increased (Fig. 6a), the protein composition of each fraction was preserved, as indicated by the similar patterns of protein bands detected after SDS gel electrophoresis (Fig. 6b). The main component in fractions $\mathrm{C} 1$ to $\mathrm{C} 4$ and in fraction $\mathrm{C} 8 \mathrm{~b}$ was MBP and its differently charged isomers identified by mass spectrometry by electrospray ionization and partial sequence analysis after cyanogens bromide cleavage (Boulias et al., 1995). Intriguingly, the main component of the fraction $\mathrm{C} 8 \mathrm{a}$, which was consistently increased in MS patients (Fig. 6a) was identified as stathmin by MALDI-TOF mass spectrometry and was further confirmed by partial sequencing and Western blot analysis (Fig. $6 b$ ). The $17-18 \mathrm{kDa}$ protein bands in fractions $\mathrm{C} 1$ to $\mathrm{C} 4$ and in $\mathrm{C} 8 \mathrm{~b}$, but not in $\mathrm{C} 8 \mathrm{a}$, were immunoreactive with antibodies specific for MBP (Fig. 6b), whereas the bands in fraction C8a reacted only with an antibody against the C-terminal part of stathmin (Koppel et al., 1990). The stathmin antibody identified the protein as a doublet in Western blot analysis of the C8a fraction (Fig. 6b) and of in total protein lysates extracted from normal-appearing white matter samples from MS and control brains (Fig. $6 c$ ). The $17 \mathrm{kDa}$ stathmin-immunoreactive band is the likely result of the $\mathrm{N}$-terminal cleavage of the $18 \mathrm{kDa}$ stathmin. The quantitative differences in stathmin protein levels between MS patients and controls were further assessed by slot blot analysis of the protein samples (Fig. $6 d$ ). The mean value of intensity of the stathmin-immunoreactive band in normal brain was a $47 \pm 5$ pixel area, whereas the mean value of intensity for MS brain samples was a $90.25 \pm 19$ pixel area (Fig. $6 e$ ).

Together, these data demonstrate that stathmin is expressed at higher levels in the brain of MS patients than in normal controls. Its overexpression is predominantly found in the normalappearing white matter and in myelin preparations. Because in the bioptic samples from MS patients stathmin-positive cells were predominantly observed in areas with a significant inflammatory component, we asked whether inflammatory cytokine could regulate the levels of this protein. To test this hypothesis, primary cultures of oligodendrocyte were treated with either tumor necrosis factor $\alpha$ (TNF $\alpha$ ) or TGF $\beta$ for $24 \mathrm{~h}$, and the levels of stathmin were compared with those observed in untreated cultures. Both cytokine treatments resulted in increased mRNA and protein (Fig. $6 f$ ) levels of stathmin compared with untreated controls. These data suggested that stathmin expression is favored by inflammation.

\section{Stathmin overexpression in progenitors favors the maintenance of a simple morphology}

The high levels of stathmin detected in the immunohistochemical and biochemical analysis of MS tissue led us to investigate the functional consequences of stathmin overexpression in cells of the oligodendrocyte lineage. Briefly, A2B5-immunopanned progenitors were transfected either with EGFP or with a myc-tagged stathmin cDNA using electroporation or FUGENE 6 and were then plated on poly-lysine-coated (Fig. $7 a-d$ ) or laminin-coated 
(Fig. $7 f-i$ ) chamber slides. The morphological differentiation was assessed after the removal of mitogens from the culture medium for $24 \mathrm{~h}$. Transfected cells were identified by EGFP (Fig. $7 a, b, f, g$ ) or myctag (Fig. $7 c, d, h, i$ ) immunoreactivity, and their morphology was identified by $\mathrm{O} 4$ labeling of the membrane processes (Fig. $7 b, d, g, i)$. Transfected cells were classified according to their morphology into simple, intermediate, and complex phenotype, as described previously (MarinHusstege et al., 2002; A. Liu et al., 2003). Of the $365 \mathrm{EGFP}+/ \mathrm{O} 4+$ double-reactive cell cultured on poly-lysine and counted in three separate experiments, $53.7 \pm 2 \%$ of the cells were classified as "intermediate morphology," as defined by the presence of secondary and tertiary branches, whereas $40.8 \pm 0.8 \%$ were identified as "complex morphology," characterized by the presence of several interlaced fine branches. Only $5.5 \pm 2.7 \%$ of cells displayed a "simple morphology," defined by primary branches and the absence of secondary and tertiary processes. In contrast, the stathmin-overexpressing cells, in the same culture conditions, were unable to generate complex branches (Fig. $7 c, d$ ). The majority of the 190 myc-tag+/O4+ stathmin-overexpressing cells was classified as simple $(x=51.3 \pm 5.2 \%)$ and as intermediate $(x=45.9 \pm 2.9 \%)$, and only $2.8 \pm 2.5 \%$ of cells displayed a complex morphology (Fig. 7e). Similar results were observed in cells plated on laminin substrate. After removal of mitogen for $24 \mathrm{~h}$, the majority of EGFP-transfected cells showed intermediate $(65.1 \pm 2.8 \%)$ and complex (24.2 $\pm 4.6 \%)$ morphology. Only $10.7 \pm 2.1 \%$ of EGFP-transfected cells showed simple morphology. However, on laminin-coated slides, the majority of stathmin-transfected cells showed very simple morphology $(73.7 \pm 1.2 \%)$. Only $21.2 \pm 4.7 \%$ of the cells showed intermediate morphology, and $5.1 \pm 4.7 \%$ of the cells showed complex morphology (Fig. 7j). The difference in the percentage of cells with simple morphology between the transfected and untransfected cells was statistically significant $(p<0.005)$. We conclude that downregulation of stathmin is crucial for the complex morphological changes observed during oligodendrocyte progenitor differentiation and that high levels of this molecule in progenitors may favor migration by maintaining the cells in a simple morphology.

\section{Elevated stathmin levels in differentiated oligodendrocytes render the cells more prone to apoptotic stimuli}

Because the stability of the microtubule network is crucial for myelin maintenance and proper function, we asked whether the persistence of high levels of stathmin in differentiating oligodendrocytes could affect cellular viability, by interfering with the function of the microtubule network. To address this issue, myctagged stathmin and EGFP-transfected progenitors were exposed to an apoptotic stimulus, either at the progenitor stage (Fig. 8a) or after $3 \mathrm{~d}$ of differentiation (Fig. $8 b$ ), the loosely attached cells were removed by several washes, and the number of surviving cells were counted. Glucose deprivation was the apoptotic stimulus of choice because it affects the energetic metabolism of the cell (Almeida et al., 2002; Y. Liu et al., 2003; Majewski et al., 2004), thus mimicking the environment encountered by oligodendrocytes in pathological conditions such as MS (Roelcke et al., 1997; Bakshi et al., 1998).

No statistically significant difference $(p=0.11)$ was observed in the percentage of surviving cells in the myc-stathmintransfected progenitors (survival, $91.2 \pm 6.4 \%$; total number of viable cells, 2230) compared with EGFP-transfected controls (Fig. 8a) (total number of viable cells, 2443), thereby confirming that high levels of this protein in early migratory progenitors were compatible with survival. In contrast, the number of surviving stathmin-transfected cells after differentiation was significantly lower than the number of cells in EGFP controls $(p<0.002)$. The myc-stathmin-expressing differentiating oligodendrocytes were more susceptible to apoptosis than the controls (Fig. $8 b$ ), because only $52.2 \pm 4.5 \%$ of myc-tagged transfected cells (total number of cells counted, 214) survived a glucose-deprivation stimulus compared with EGFP-transfected controls (total number of viable cells, 410). To confirm that the cell loss observed in stathmin 

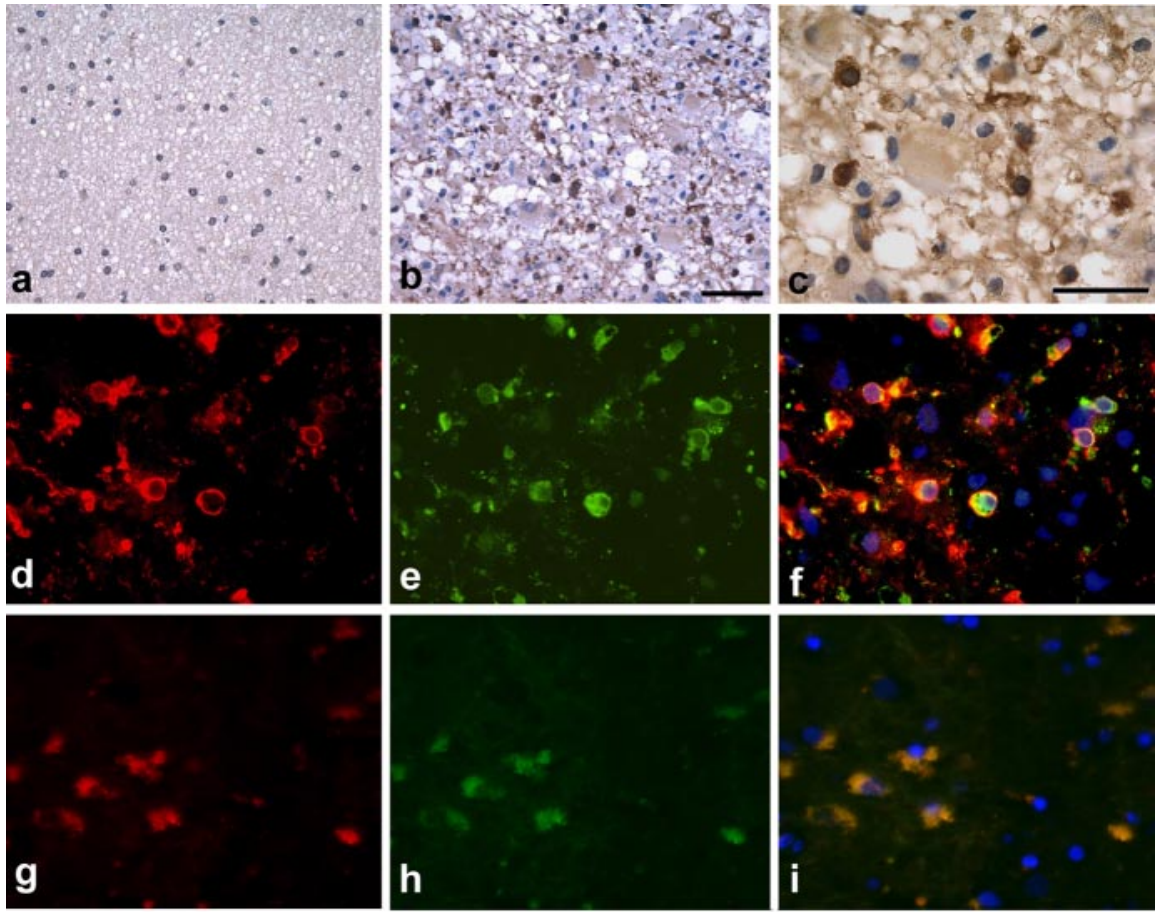

Figure 5. Increased stathmin levels in the brain of MS patients. Very few immunoreactive cells (dark brown staining) were found in the white matter of control brain sections counterstained with hematoxylin (purple staining in $a$ ). In contrast, numerous stathmin-immunoreactive oligodendrocyte-like cells (dark brown staining) were found in the highly inflamed lesional area in MS patients ( $b$; original magnification, $400 \times$ ). Stathmin (brown staining) was found predominantly in the soma and in the processes of oligodendrocytes in MS lesions counterstained with hematoxylin ( $c$; original magnification, $1000 \times)$. Note that no stathmin immunoreactivity was observed in axons (c). Immunofluorescence of MS brain lesions using anti-CNPase (red; $d$ ) and stathmin (green; $e$ ) antibodies further confirmed that the immunoreactive cells belong to the oligodendrocyte lineage, as seen in the overlay of the two panels $(f)$. The stathmin-positive cells (green; $h$ ) in MS brain lesions are also APC/CC1 immunoreactive (red; $g$ ). Double-stained cells appear yellow (i).

overexpressors was attributable to enhanced susceptibility to apoptotic stimuli, we repeated the experiment in the differentiating cells and assessed the number of TUNEL + cells (Fig. $8 c-e$ ). Consistent with previous results, the percentage of apoptotic cells was higher in the myc-tag + stathmin-transfected population $(x=$ $19.5 \pm 3.2 \%$; total number of cells counted, 209) compared with pcDNA-transfected controls $(x=6.4 \pm 2.1 \%$; total number of cells counted, 337$)$, thus resulting in a statistically significant difference between the two populations $(p<0.005)$.

Together, these results suggest that high levels of stathmin in progenitors favor a simple morphology but do not affect survival, whereas in differentiated cells, they may enhance the susceptibility to apoptotic stimuli.

\section{Discussion}

A better understanding of the functional role of developmentally regulated molecules reexpressed in disease state is crucial for the development of repair strategies based on the recruitment of endogenous progenitors. We have previously identified stathmin, a developmentally regulated tubulin-sequestering and microtubuleinterfering molecule, as one of the transcripts that is epigenetically downregulated during oligodendrocyte differentiation in vitro (A. Liu et al., 2003). Given the importance of the microtubule network for the maintenance and the stability of a functional myelin membrane (Ainger et al., 1993; Benjamins and Nedelkoska 1994; Carson et al., 1998; Song et al., 2001), we asked whether the levels of this molecule were also modulated in demyelinating conditions. Here, we describe the reexpression of stathmin in the brain of MS patients and in animal models of demyelination.
It has been reported previously that stathmin is widely expressed in the embryonic and neonatal brain and then progressively declines during development (Koppel et al., 1990; Amat et al., 1991). In the adult rat brain, immunoreactivity is retained in highly proliferative areas, such as the adult SVZ (Amat et al., 1991). Consistent with these studies, we also observed strong stathmin immunoreactivity in multipotential progenitors in the SVZ of 4-week-old normal mice (Fig. 2). The role of SVZ cells in generating glial progenitors has been characterized extensively in the neonatal brain (Zerlin et al., 2004). It has also been demonstrated that these SVZ cells tend to reacquire this gliogenic potential in response to demyelinating conditions (Gensert and Goldman, 1997; NaitOumesmar et al., 1999; Picard-Riera et al., 2002). Stathmin expression in these cells is crucial for their migration. This role has been highlighted recently by the experiments of Jin et al. (2004), who have shown that decreased stathmin levels in these cells inhibit their mobilization from the SVZ. The linkage between stathmin levels and migration is also supported by studies on tumoral cell lines in which stathmin levels correlate with an invasive phenotype (Balachandran et al., 2003; Walter-Yohrling et al., 2003). Our studies in vitro, in cultured oligodendrocyte progenitors, indicate that stathmin is elevated by stimuli favoring migrations (i.e., PDGF and bFGF) (Fig. 1), and its expression is downregulated by differentiative stimuli, such as mitogen withdrawal and growth on a laminin substrate, known to favor membrane spreading and myelin formation (Buttery and ffrench-Constant, 1999; Chun et al., 2003). In vivo, in physiological conditions, stathmin is expressed by migratory precursors labeled by PSA-NCAM (Fig. 2). However, its levels progressively decrease as these cells develop into mature $\mathrm{CC} 1+$ oligodendrocytes (Fig. 2). The population of stathminexpressing PSA-NCAM+ cells is increased after a chemically induced demyelinated lesion (Figs. 3, 4). Downregulation of stathmin levels from progenitors to mature oligodendrocyte is also observed during remyelination of the chemical lesion (Figs. 3, 4).

From these data, we conclude that stathmin expression is elevated in SVZ precursor cells, where it labels a migratory population of progenitor cells, and it is low in mature oligodendrocytes, as observed during normal development or in remyelination in the absence of an inflammatory component.

In contrast, in pathological conditions associated with inflammatory demyelination, stathmin is predominantly found in $\mathrm{CNP}+$ oligodendrocytes, and it appears to be localized mostly in the soma but also in the processes of the immunoreactive cells (Fig. 5).

To determine whether the increase in stathmin observed in the brain of MS patients occurred in newly formed oligodendrocytes, in preexisting myelinating cells, or in both populations, we conducted a careful immunohistochemical analysis of bioptic material, as well as a detailed biochemical characterization of stathmin in the white matter samples of patients and control 
subjects. Using antibodies against MAG, MOG, and MBP combined with PLP in situ hybridization, and following previously described morphological criteria for the analysis of myelin (Bruck and Stadelmann, 2003), stathmin + cells were classified according to the specific histopathology of each sample. Interestingly, stathmin immunoreactivity was present in samples characterized by oligodendrocytic loss and severe demyelination as well as in those characterized by extensive remyelination and "shadow" plaques. From these data, we conclude that the increase in stathmin protein levels correlate with the presence of inflammatory demyelination, rather that to a specific stage of oligodendrocyte development.

Increased levels of stathmin were also observed using an independent approach based on the biochemical characterization of the white matter samples isolated from the brain of MS patients compared with controls (Fig. 6). It was previously reported that after acid extraction followed by cation exchange chromatography, the white matter of MS patients consistently yielded much higher levels of a specific fraction, called C8a, compared with controls (Moscarello et al., 1994). The main components of this fraction were two previously unidentified bands of 17 and 18 $\mathrm{kDa}$. Here, using mass spectrometry, these components were unequivocally identified as stathmin (Fig. 6). The increased stathmin levels in MS brain were further confirmed by Western blot analysis of protein lysates from samples of normalappearing white matter and by immunoslot blot of the specific C8a myelin fractions. In both, normal and MS preparation stathmin appeared as a doublet of 17-18 kDa. The lower molecular weight band was the most prominent in patients and could be the result of proteolytic cleavage of the $\mathrm{N}$ terminus, because the antiserum used was specific for the last C-terminal amino acids of the molecule (Koppel et al., 1990). The $\mathrm{N}$ terminus of the molecule contains multiple phosphorylation sites responsible for the inactivation of stathmin destabilizing activity, whereas the $\mathrm{C}$ terminus contains the tubulin-binding site (Segerman et al., 2000). Therefore, it is tempting to speculate that the increased lower band observed in MS patients could result from proteolytic cleavage of the $\mathrm{N}$ terminus, thus yielding a microtubule destabilizing protein more resilient to inactivation mechanisms because of external stimuli modulating its phosphorylation state.

Together, the immunohistochemical and the biochemical data unequivocally identify increased protein levels of stathmin in the white matter oligodendrocytes of MS patients. Similar results were also obtained in a transgenic mouse model of sponta-
C
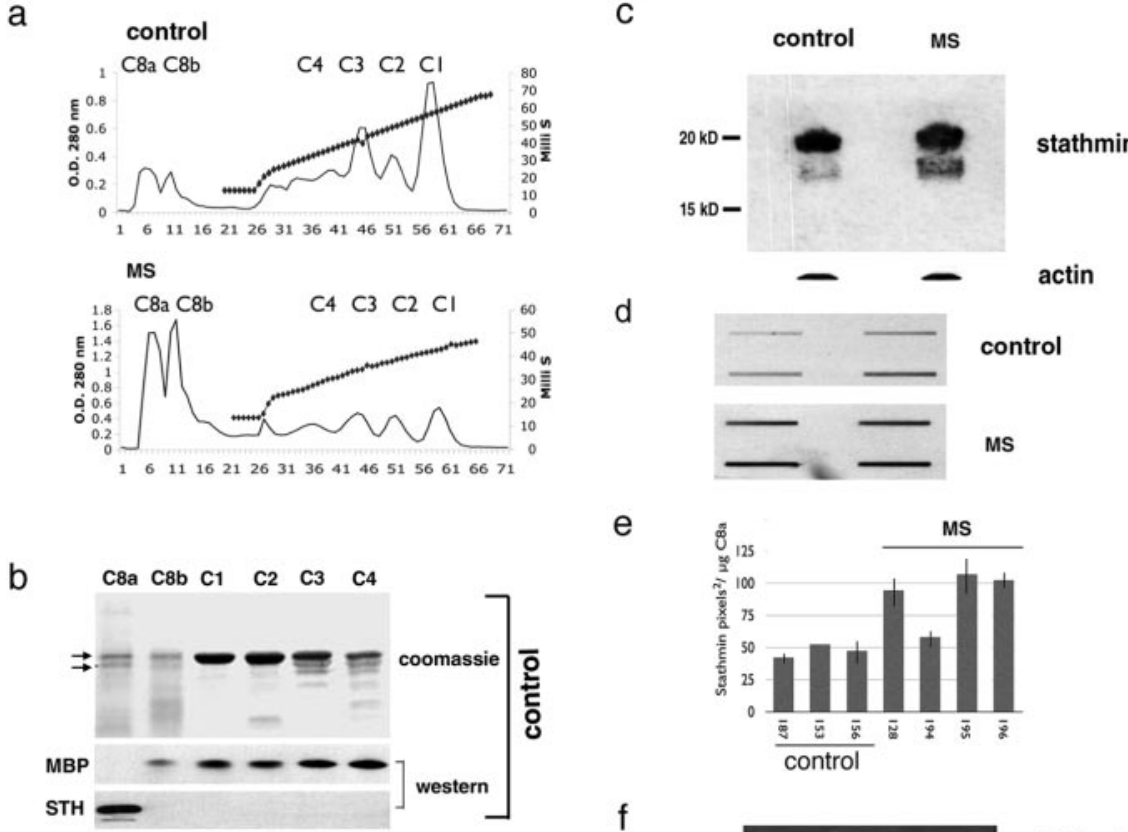

e

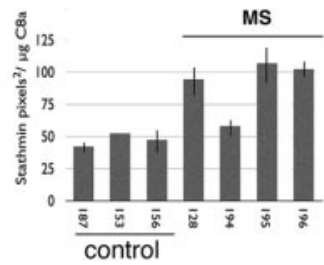

f

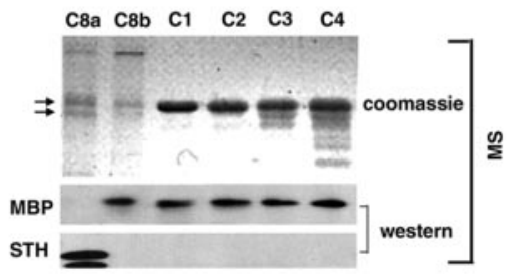

RT-PCR



stathmin actin

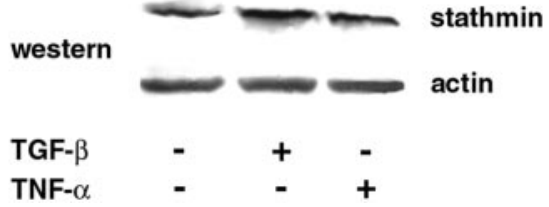

Figure 6. Increased stathmin protein levels in the brain of MS patients. To characterize the expression of stathmin in the human normal-appearing white matter from patients (MS) and normal controls (control), we adopted a fractionation method described previously for the isolation of basic proteins (Wood and Moscarello, 1989). Several fractions named C 1 to C $8 \mathrm{a}$ and C8b were isolated from the white matter samples of control and MS human brains ( $a$ ). The yield of the $\mathrm{C} 1$ to $\mathrm{C} 3$ fractions was dramatically decreased in MS patients, whereas fractions $(8 \mathrm{a}$ and $\mathrm{C} 8 \mathrm{~b}$ were increased compared with controls $(b)$. A Coomassie blue staining of equal amount of proteins isolated from these different fractions and separated by gel electrophoresis $(b$, coomassie) revealed the presence of prominent bands in the 17-18 kDa molecular weight range in each fraction (double arrows). Mass spectrometry confirmed that MBP and its variously charged isomers were the main component of the 17-18 kDa band in fractions $\mathrm{C} 1$ to $C 4$ and $(8 b$, whereas stathmin was identified with a high level of confidence (individual ion score of $>33$ ) as the main band in fraction (8a. Each experiment was performed on samples from three normal and four patients and performed in triplicate. Western blot analysis with antibodies against MBP or stathmin confirmed the mass spectrometry results $(b)$. Note that stathmin was identified as a doublet with the lower band significantly increased in MS patients. Western blot analysis revealed a similar increase in the stathmin doublet also in whole-cell lysate preparations obtained from the normal-appearing white matter of MS patients compared with age- and sex-matched samples. Actin was used as loading control ( $c$ ). Quantitative slot-immunoblot analysis of the acid-extracted white matter 8 fractions isolated from control and MS brain samples further confirmed the increased stathmin levels in MS brain compared with control (d). Quantification of these results is shown as a bar graph $(e)$. Although some variability was observed for the various patients, stathmin levels in the membrane fractions isolated from MS brain tissue were almost twice as high as the levels found in the control brains. The effect of inflammatory cytokines on stathmin expression in the oligodendrocyte lineage was therefore tested in vitro, by treating differentiating oligodendrocyte progenitors (OL) with $0.2 \mu \mathrm{g} / \mathrm{ml} \mathrm{TGF}-\beta$ (OL plus TGF- $\beta$ ) or TNF- $\alpha$ (OL plus TNF- $\alpha$ ) for $24 \mathrm{~h}$ after mitogen withdrawal. $f$, Cytokine treatment of primary cultured cells resulted in increased levels of stathmin mRNA, as detected by RT-PCR, and protein, as detected by Western blot analysis. Actin was used as a control for equal loading.

neous demyelination, the ND4 mouse (Mastronardi et al., 1993, 1996). In these animals, stathmin immunoreactivity was observed in damaged oligodendrocytes in the corpus callosum and in protein extracts from the myelin fraction (data not shown). Therefore, our data suggest that in physiological conditions and during development, stathmin is expressed in early progenitors in the SVZ and is rapidly downregulated after differentiation. In contrast, in inflammatory demyelination, such as in the brain of MS patients, stathmin is expressed in mature oligodendrocytes. Consistent with a role for inflammation in elevating stathmin 

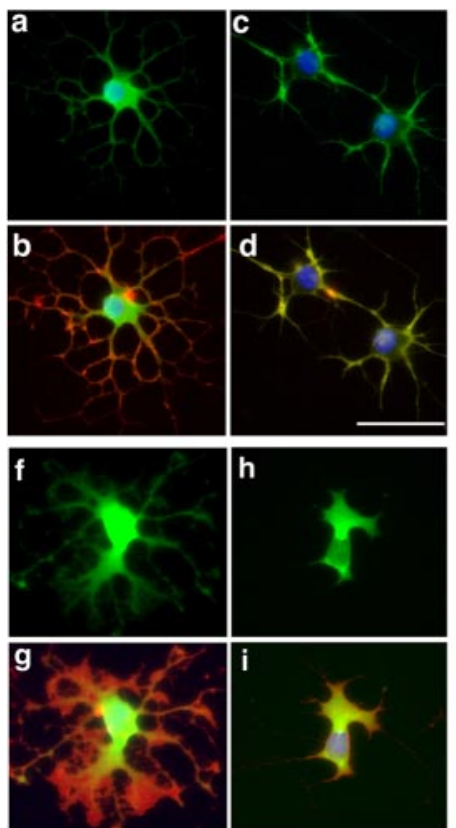

e
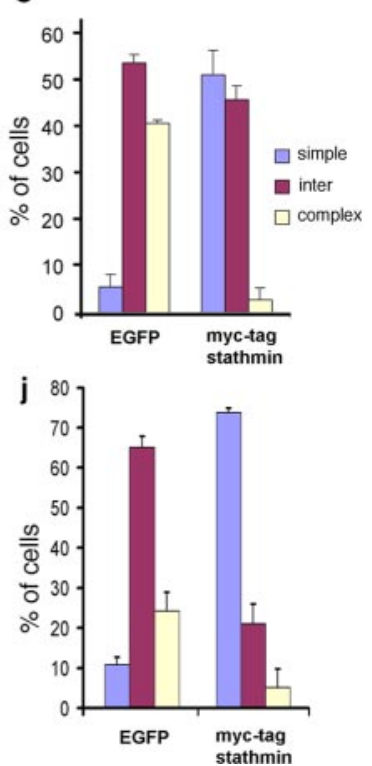

Figure 7. Stathmin gain-of-function in progenitors prevents the attainment of a highly branched phenotype. Immunoselected A2B5-positive rat cortical oligodendrocyte progenitors were electroporated with a mammalian expression vector containing either $\operatorname{EGFP}(a, b, f, g)$ or myc-tagged stathmin $(c, d, h, i)$ and then plated on poly-lysine-coated $(a-d)$ or laminin-coated $(f-i)$ chamber slides. The day after transfection, cells were induced to differentiate in mitogenfree chemically defined medium for $24 \mathrm{~h}$ and then fixed. Double immunofluorescence for 04 ( red; $b, d, g, i$ ) and either GFP (green; $a, b, f, g$ ) or myc-tag (green; $c, d, h, i$ ) was used to identify the morphology of the transfected cells. DAPI (blue; $a-d, f-i$ ) was used as a nuclear counterstain. A total of $>500$ transfected cells from triplicate experiments were classified according to their morphology as simple, intermediate, or complex and then quantified $(e, j)$. Stathmin overexpression increased cells with simple and intermediate morphology and prevented the attainment of a complex phenotype. Note that this inhibitory effect on branching occurred independently of the substrate. The difference between the number of cells with simple morphology in the GFP-transfected versus the myc-stathmin-transfected groups was statistically significant $(p<0.005)$. Scale bar, $100 \mu \mathrm{m}$.

levels, in vitro treatment of cultured oligodendrocytes with two inflammatory cytokines that have been shown previously to induce death of differentiated oligodendrocytes, TGF $\beta$ and TNF $\alpha$ (Yu et al., 2000; Schuster et al., 2003), increased the levels of this molecule. Remarkably, these results are also in agreement with the enhanced susceptibility to apoptosis observed in stathminoverexpressing cells (Fig. 8).

The functional consequences of elevated stathmin levels in cells of the oligodendrocyte lineage were further assessed by using a gain-of-function approach. Overexpression of stathmin in oligodendrocyte progenitors significantly inhibited branching, thus resulting in a simple morphology characteristic of the migratory phenotype (Fig. 7). Maintenance of the stathmin-overexpressing cells in differentiation conditions, however, rendered the cells more susceptible to apoptotic stimuli (Fig. 8).

Together, these data suggest that upregulation of stathmin could provide a pathogenetic mechanism able to explain the reported success of therapies aimed at promoting the stability of the microtubule network in demyelinating diseases (Moscarello et al., 2002). In agreement with this hypothesis, treatment of mice with active or passive experimental allergic encephalomyelitis (Cao et al., 2000; Pritzker and Moscarello, 1998) and of ND4 transgenics (Moscarello et al., 2002) with microtubule stabilizing drugs (i.e., Taxol) have shown a remarkable improvement in the neuropathology and clinical score. Therefore, the results of the
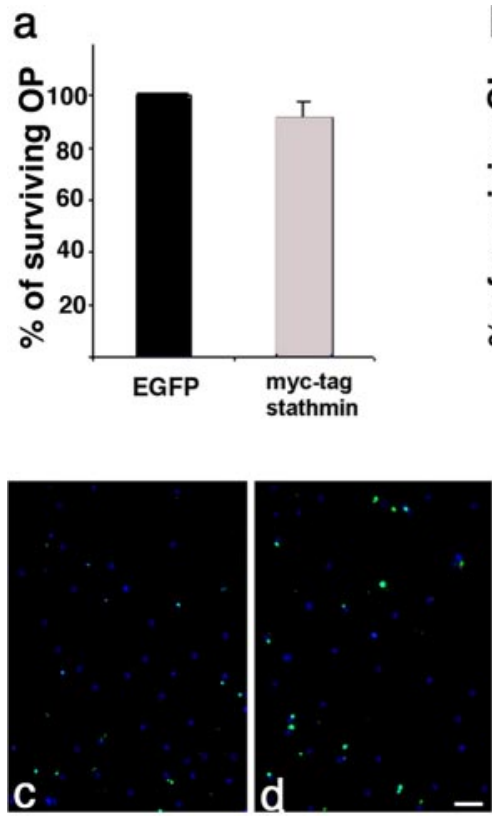

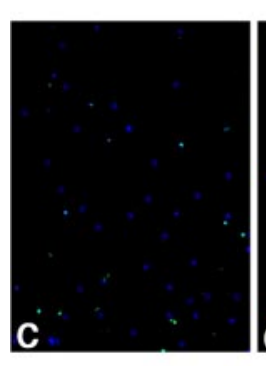

b
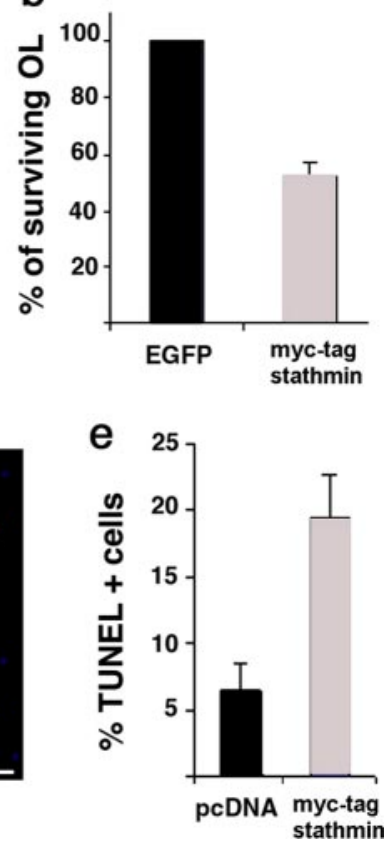

Figure 8. Elevated levels of stathmin in differentiating, but not in proliferating, oligodendrocyte progenitors enhance the susceptibility of these cells to apoptotic stimuli. Myc-tagged stathmin- and EGFP-transfected progenitors kept in PDGF plus bFGF $(a)$ or allowed to differentiate for $3 \mathrm{~d}$ by mitogen removal $(b)$ were subject to glucose deprivation during the last $24 \mathrm{~h}$, and the number of surviving transfectants was calculated. Note that high levels of stathmin did not affect survival of proliferating progenitors $(a)$, whereas it enhanced the susceptibility of differentiating cells to death $(b)$. To confirm that in stathmin-overexpressing cells were apoptotic, TUNEL + cells (green; $c, d$ ) were counted in pcDNA-transfected $(c)$ and myc-stathmintransfected $(d)$ cells. The percentage of TUNEL + cells was calculated by referring the number to the total number of DAPI + cells (blue; $c, d$ ), and the data are presented as a bar graph $(e)$. The difference in apoptotic cells between the two groups of differentiating oligodendrocytes was statistically significant $(p<0.005)$. Scale bar, $100 \mu \mathrm{m}$.

interdisciplinary and multifaceted experimental approach adopted in this study identify stathmin in particular and the microtubule network in general as an important target in demyelinating disorders.

In conclusion, our data suggest that high stathmin levels are characteristic of migratory progenitors. However, as the cell begins to differentiate, its levels decrease to allow the microtubule network to form properly. Therefore, we suggest that increased stathmin in newly formed or in preexisting oligodendrocytes in both cases could result in microtubule instability and improper function of the cytoskeletal apparatus (Ainger et al., 1993; Benjamins and Nedelkoska 1994; Carson et al., 1998; Song et al., 2001). Changes in morphology, myelin stability, and possibly survival could result from increased stathmin levels in mature oligodendrocytes. Future studies using conditional system and possibly transgenic mice will allow us to further test this possibility.

\section{References}

Ainger K, Avossa D, Morgan F, Hill SJ, Barry C, Barbarese E, Carson JH (1993) Transport and localization of exogenous myelin basic protein mRNA microinjected into oligodendrocytes. J Cell Biol 123:431-441.

Almeida A, Delgado-Esteban M, Bolanos JP, Medina JM (2002) Oxygen and glucose deprivation induces mitochondrial dysfunction and oxidative stress in neurones but not in astrocytes in primaryculture. J Neurochem 81:207-217.

Amat JA, Fields KL, Schubart UK (1991) Distribution of phosphoprotein 
p19 in rat brain during ontogeny: stage-specific expression in neurons and glia. Dev Brain Res 60:205-218.

Anderson DJ, Axel R (1985) Molecular probes for the development and plasticity of neural crest derivatives. Cell 42:649-662.

Bakshi R, Miletich RS, Kinkel PR, Emmet ML, Kinkel WR (1998) Highresolution fluorodeoxyglucose positron emission tomography shows both global and regional cerebral hypometabolism in multiple sclerosis. J Neuroimaging 8:228-234.

Balachandran R, Welsh MJ, Day BW (2003) Altered levels and regulation of stathmin in paclitaxel-resistant ovarian cancer cells. Oncogene 22:8924-8930.

Belmont LD, Mitchison TJ (1996) Identification of a protein that interacts with tubulin dimers and increases the catastrophe rate of microtubules. Cell 84:623-631.

Ben-Hur T, Rogister B, Murray K, Rougon G, Dubois-Dalcq M (1998) Growth and fate of PSA-NCAM+ precursors of the postnatal brain. J Neurosci 18:5777-5788.

Benjamins JA, Nedelkoska L (1994) Maintenance of membrane sheets by cultured oligodendrocytes requires continuous microtubule turnover and Golgi transport. Neurochem Res 19:631-639.

Boulias C, Pang H, Mastronardi F, Moscarello MA (1995) The isolation and characterization of four myelin basic proteins from the unbound fraction during CM52 chromatography. Arch Biochem Biophys 322:174-182.

Bruck W, Stadelmann C (2003) Inflammation and degeneration in multiple sclerosis. Neurol Sci 24 [Suppl 5]:S265-S267.

Buttery PC, ffrench-Constant C (1999) Laminin-2/integrin interactions enhance myelin membrane formation by oligodendrocytes. Mol Cell Neurosci 14:199-212.

Camoletto P, Peretto P, Bonfanti L, Manceau V, Sobel A, Fasolo A (1997) The cytosolic phosphoprotein stathmin is expressed in the olfactory system of the adult rat. NeuroReport 8:2825-2829.

Cao L, Sun D, Cruz T, Moscarello MA, Ludwin SK, Whitaker JN (2000) Inhibition of experimental allergic encephalomyelitis in the Lewis rat by paclitaxel. J Neuroimmunol 108:103-111.

Carson JH, Kwon S, Barbarese E (1998) RNA trafficking in myelinating cells. Curr Opin Neurobiol 8:607-612.

Charbaut E, Curmi PA, Ozon S, Lachkar S, Redeker V, Sobel A (2001) Stathmin family proteins display specific molecular and tubulin binding properties. J Biol Chem 276:16146-16154.

Cheifetz S, Moscarello MA (1985) Effect of bovine basic protein charge microheterogeneity on protein-induced aggregation of unilamellar vesicles containing a mixture of acidic and neutral phospholipids. Biochemistry 24:1909-1914.

Chun SJ, Rasband MN, Sidman RL, Habib AA, Vartanian T (2003) Integrinlinked kinase is required for laminin-2-induced oligodendrocyte cell spreading and CNS myelination. J Cell Biol 163:397-408.

Curmi PA, Andersen SS, Lachkar S, Gavet O, Karsenti E, Knossow M, Sobel A (1997) The stathmin/tubulin interaction in vitro. J Biol Chem 272:25029-25036.

Decker L, Avellana-Adalid V, Nait-Oumesmar B, Durbec P, Baron-Van Evercooren A (2000) Oligodendrocyte precursor migration and differentiation: combined effects of PSA residues, growth factors, and substrates. Mol Cell Neurosci 16:422-439.

Decker L, Picard-Riera N, Lachapelle F, Baron-Van Evercooren A (2002) Growth factor treatment promotes mobilization of young but not aged adult subventricular zone precursors in response to demyelination. J Neurosci Res 69:763-771.

Doetsch F, Garcia-Verdugo JM, Alvarez-Buylla A (1997) Cellular composition and three-dimensional organization of the subventricular germinal zone in the adult mammalian brain. J Neurosci 17:5046-5061.

Franklin KBJ, Paxinos G (1997) The mouse brain in stereotaxic coordinates. San Diego: Academic.

Gavet O, El Messari S, Ozon S, Sobel A (2002) Regulation and subcellular localization of the microtubule-destabilizing stathmin family phosphoproteins in cortical neurons. J Neurosci Res 68:535-550.

Gensert JM, Goldman JE (1997) Endogenous progenitors remyelinate demyelinated axons in the adult CNS. Neuron 19:197-203.

Hafner C, Schmitz G, Meyer S, Bataille F, Hau P, Langmann T, Dietmaier W, Landthaler M, Vogt T (2004) Differential gene expression of Eph receptors and ephrins in benign human tissues and cancers. Clin Chem 50:490-499.

Hailat N, Strahler J, Melhem R, Zhu XX, Brodeur G, Seeger RC, Reynolds CP,
Hanash S (1990) N-myc gene amplification in neuroblastoma is associated with altered hosphorylation of a proliferation related polypeptide (Op18). Oncogene 5:1615-1618.

Himi T, Okazaki T, Wang H, McNeill TH, Mori N (1994) Differential localization of SCG10 and p19/stathmin messenger RNAs in adult rat brain indicates distinct roles for these growth-associated proteins. Neuroscience 60:907-926.

Jin K, Mao XO, Cottrell B, Schillling B, Xie L, Row RH, Sun Y, Peel A, Childs J, Gendeh G, Gibson BW, Greenberg DA (2004) Proteomic and immunochemical characterization of a role for stathmin in adult neurogenesis. FASEB J 18:287-299.

John GR, Shankar SL, Shafit-Zagardo B, Massimi A, Lee SC, Raine CS, Brosnan CF (2002) Multiple sclerosis: re-expression of a developmental pathway that restricts oligodendrocyte maturation. Nat Med 8:1115-1121.

Koppel J, Boutterin MC, Doye V, Peyro-Saint-Paul H, Sobel A (1990) Developmental tissue expression and phylogenetic conservation of stathmin, a phosphoprotein associated with cell regulations. J Biol Chem 265:3703-3707.

Lawler S, Gavet O, Rich T, Sobel A (1998) Stathmin overexpression in 293 cells affects signal transduction and cell growth. FEBS Lett 421:55-60.

Levine JM, Reynolds R (1999) Activation and proliferation of endogenous oligodendrocyte precursor cells during ethidium bromide-induced demyelination. Exp Neurol 160:333-347.

Liu A, Muggironi M, Marin-Husstege M, Casaccia-Bonnefil P (2003) Oligodendrocyte process outgrowth in vitro is modulated by epigenetic regulation of cytoskeletal severing proteins. Glia 44:264-274.

Liu Y, Song XD, Liu W, Zhang TY, Zuo J (2003) Glucose deprivation in duces mitochondrial dysfunction and oxidative stress in PC12 cell line. J Cell Mol Med 7:49-56.

Majewski N, Nogueira V, Robey RB, Hay N (2004) Akt inhibits apoptosis downstream of BID cleavage via a glucose-dependent mechanism involving mitochondrial hexokinases. Mol Cell Biol 24:730-740.

Marin-Husstege M, Muggironi M, Liu A, Casaccia-Bonnefil P (2002) Histone deacetylase activity is necessary for oligodendrocyte lineage progression. J Neurosci 22:10333-10345.

Mastronardi FG, Ackerley CA, Arsenault L, Roots BI, Moscarello MA (1993) Demyelination in a transgenic mouse: a model for multiple sclerosis. J Neurosci Res 36:315-324.

Mastronardi FG, Ackerley CA, Roots BI, Moscarello MA (1996) Loss of myelin basic protein cationicity in DM20 transgenic mice is dosage dependent. J Neurosci Res 44:301-307.

McCarthy KD, de Vellis J (1980) Preparation of separate astroglial and oligodendroglial cell cultures from rat cerebral tissue. J Cell Biol 85:890-902.

Moscarello MA, Wood DD, Ackerley C, Boulias C (1994) Myelin in multiple sclerosis is developmentally immature. J Clin Invest 94:146-154.

Moscarello MA, Mak B, Nguyen TA, Wood DD, Mastronardi F, Ludwin SK (2002) Paclitaxel (Taxol) attenuates clinical disease in a spontaneously demyelinating transgenic mouse and induces remyelination. Mult Scler 8:130-138.

Nait-Oumesmar B, Decker L, Lachapelle F, Avellana-Adalid V, Bachelin C, Van Evercooren AB (1999) Progenitor cells of the adult mouse subventricular zone proliferate, migrate and differentiate into oligodendrocytes after demyelination. Eur J Neurosci 11:4357-4366.

Okazaki T, Himi T, Peterson C, Mori N (1993) Induction of stathmin mRNA during liver regeneration. Genomics 18:360-373.

Ozon S, Maucuer A, Sobel A (1997) The stathmin family—molecular and biological characterization of novel mammalian proteins expressed in the nervous system. Eur J Biochem 248:794-806.

Ozon S, Byk T, Sobel A (1998) SCLIP: a novel SCG10-like protein of the stathmin family expressed in the nervous system. J Neurochem 70:2386-2396.

Ozon S, El Mestikawy S, Sobel A (1999) Differential, regional, and cellular expression of the stathmin family transcripts in the adult rat brain. J Neurosci Res 56:553-564.

Pasmantier R, Danoff A, Fleischer N, Schubart UK (1986) P19, a hormonally regulated phosphoprotein of peptide hormone-producing cells: secretagogue-induced phosphorylation in AtT-20 mouse pituitary tumor cells and in rat and hamster insulinoma cells. Endocrinology 119:1229-1238.

Pellier-Monnin V, Astic L, Bichet S, Riederer BM, Grenningloh G (2001) 
Expression of SCG10 and stathmin proteins in the rat olfactory system during development and axonal regeneration. J Comp Neurol 433:239-254.

Peschanski M, Hirsch E, Dusart I, Doye V, Marty S, Manceau V, Sobel A (1993) Stathmin: cellular localization of a major phosphoprotein in the adult rat and human CNS. J Comp Neurol 337:655-668.

Picard-Riera N, Decker L, Delarasse C, Goude K, Nait-Oumesmar B, Liblau R, Pham-Dinh D, Evercooren AB (2002) Experimental autoimmune encephalomyelitis mobilizes neural progenitors from the subventricular zone to undergo oligodendrogenesis in adult mice. Proc Natl Acad Sci USA 99:13211-13216.

Pritzker LB, Moscarello MA (1998) A novel microtubule independent effect of paclitaxel: the inhibition of peptidylarginine deiminase from bovine brain. Biochim Biophys Acta 1388:154-160.

Riedel A, Miettinen R, Stieler J, Mikkonen M, Alafuzoff I, Soininen H, Arendt T (2003) Reelin-immunoreactive Cajal-Retzius cells: the entorhinal cortex in normal aging and Alzheimer's disease. Acta Neuropathol (Berl) 106:291-302.

Roelcke U, Kappos L, Lechner-Scott J, Brunnschweiler H, Huber S, Ammann W, Plohmann A, Dellas S, Maguire RP, Missimer J, Radu EW, Steck A, Leenders KL (1997) Reduced glucose metabolism in the frontal cortex and basal ganglia of multiple sclerosis patients with fatigue: a $18 \mathrm{~F}$ fluorodeoxyglucose positron emission tomography study. Neurology 48:1566-1571.

Schubart UK (1988) Expression of phosphoprotein p19 in brain, testis, and neuroendocrine tumor cells. Developmental regulation in rat brain. J Biol Chem 263:12156-12160.

Schubart UK, Banerjee MD, Eng J (1989) Homology between the cDNAs encoding phosphoprotein p19 and SCG10 reveals a novel mammalian gene family preferentially expressed in developing brain. DNA 8:389-398.

Schuster N, Bender H, Rossler OG, Philippi A, Dunker N, Thiel G, Krieglstein K (2003) Transforming growth factor-beta and tumor necrosis factoralpha cooperate to induce apoptosis in the oligodendroglial cell line OLIneu. J Neurosci Res 273:324-333.

Segerman B, Larsson N, Holmfeldt P, Gullberg M (2000) Mutational analysis of op 18/stathmin-tubulin-interacting surfaces. Binding cooperativity controls tubulin GTP hydrolysis in the ternary complex. J Biol Chem 275:35759-35766.

Sequeira Lopez ML, Gomez RA (2004) The role of angiotensin II in kidney embryogenesis and kidney abnormalities. Curr Opin Nephrol Hypertens 13:117-122.

She YM, Wang GQ, Loboda A, Ens W, Standing KG, Burczynski FJ (2002) Sequencing of rat liver cytosolic proteins by matrix-assisted laser desorption ionization-quadrupole time-of-flight mass spectrometry following electrophoretic separation and extraction. Anal Biochem 310:137-147.

Sobel A, Taishjian Jr AH (1983) Distinct patterns of cytoplasmic protein phosphorylation related to regulation of synthesis and release of prolactin by GH cells. J Biol Chem 258:10312-10324.

Song J, Goetz BD, Baas PW, Duncan ID (2001) Cytoskeletal reorganization during the formation of oligodendrocyte processes and branches. Mol Cell Neurosci 17:624-636.

Stadelmann C, Kerschensteiner M, Misgeld T, Bruck W, Hohlfeld R, Lassmann H (2002) BDNF and gp145trkB in multiple sclerosis brain lesions: neuroprotective interactions between immune and neuronal cells? Brain 125:75-85.

Walter-Yohrling J, Cao X, Callahan M, Weber W, Morgenbesser S, Madden SL, Wang C, Teicher BA (2003) Identification of genes expressed in malignant cells that promote invasion. Cancer Res 63:8939-8947.

Wilson R, Brophy PJ (1989) Role for the oligodendrocyte cytoskeleton in myelination. J Neurosci Res 22:439-448.

Wood DD, Moscarello MA (1989) The isolation, characterization, and lipid-aggregating properties of a citrulline containing myelin basic protein. J Biol Chem 264:5121-5127.

Woodruff RH, Franklin RJ (1999) Demyelination and remyelination of the caudal cerebellar peduncle of adult rats following stereotaxic injections of lysolecithin, ethidium bromide, and complement/anti-galactocerebroside: a comparative study. Glia 25:216-228.

Yu C, Takeda M, Soliven B (2000) Regulation of cell cycle proteins by TNFalpha and TGF-beta in cells of oligodendroglial lineage. J Neuroimmunol 108:2-10.

Zerlin M, Milosevic A, Goldman JE (2004) Glial progenitors of the neonatal subventricular zone differentiate asynchronously, leading to spatial dispersion of glial clones and to the persistence of immature glia in the adult mammalian CNS. Dev Biol 270:200-213. 